Daniel Hora *

\title{
Paradoxos do ativismo pós-digital na arte, design e arquitetura
}

Daniel Hora é professor adjunto do Departamento de Artes Visuais, da Universidade Federal do Espírito Santo. É um dos líderes do grupo de pesquisa Fresta: imagens técnicas e dispositivos errantes. É também pesquisador colaborador do Núcleo de Estética, Hermenêutica e Semiótica, vinculado ao Programa de Pós-Graduação da Faculdade de Arquitetura e Urbanismo da Universidade de Brasília. Obteve doutorado em Arte Contemporânea pela Universidade de Brasília em 2015. Foi pesquisador visitante na Universidade da Califórnia, em San Diego, como bolsista do programa Capes-Fulbright de doutorado sanduíche nos EUA. <hora.daniel@gmail.com> ORCID: 0000-0001-6582-3276
Resumo $O$ contexto tecnológico pós-digital recompõe as dinâmicas de confluência entre o político e o artístico. As ousadias experimentais baseadas no dispositivo informacional, os processos reticulares colaborativos e a automação generativa são aspectos que assumem proeminência em algumas práticas ativistas na arte, design e arquitetura. No entanto, os paradoxos persistem acerca da possibilidade de intermediação entre duas perspectivas: a da heteronomia funcional das artes aplicadas e a da autonomia do regime estético da arte contemporânea. Neste artigo, revisaremos o debate a respeito da carga crítica e insurgente encontrada em abordagens tecnológicas de duplo sentido, que ora partem da estética para o utilitário, ora se movem em direção inversa. Faremos referência a projetos de arte ativismo hacker e de design e arquitetura especulativa. Como proposta final de articulação entre essas vertentes, apresentaremos o conceito de in-utensilio crítico.

Palavras chave Disrupção estética, Tecnologias pós-digitais, Teoria e produção crítica, Design especulativo, Arte ativismo hacker.

\section{Paradoxes of post-digital activism in art, design and architecture}

Abstract Post-digital technological context re-establishes the dynamics of confluence between the political and the artistic. Experimental challenges based on informational devices, collaborative networked processes and generative automation turn into prominent features in some activist practices in art, design and architecture. However, some paradoxes persist over the possibilities of intermediation between two perspectives: the functional heteronomy of applied arts and the aesthetic regime of autonomy in contemporary art. In this paper, we will review discussions about critical and insurgent power found in double-edged technological approaches, sometimes moving from aesthetical to utilitarian effects, sometimes going in the opposite direction. We will make reference to art projects of hacker activism and speculative design and architecture. As a closing proposal to articulate these strands, we will present the concept of critical in-utensil.

Keywords Aesthetic disruption, Post-digital technologies, Critical theory and making, Speculative design, Hacker art activism.

DATJournal v.4 n.2 2019 


\section{Intercâmbios tecnológicos e sistema das artes}

A produção e o design críticos pressupõem distanciamento. Um afastamento em relação ao que é habitual nos regimes de mercado e consumo, com o qual o útil é suspendido por táticas reflexivas de contestação ou substituição alternativa. Por sua vez, o arte ativismo demanda aproximação. Com ela, o âmbito extraordinário, da fruição supostamente desinteressada da estética, passa a operar no domínio político, de modo diretamente ou indiretamente declarado, pela adoção em usos direcionados.

A tecnologia recente permite passagens fluidas entre ambos os sentidos, sem, no entanto, fundi-los. Paradoxalmente, a permanência de ambas as polaridades parece necessária para que existam modalidades de protesto, agrupáveis em um campo de intercorrências exorbitantes às lógicas de particionamento dualista que separam a conveniência do utensílio do deleite lúdico com o inutensílio - ou seja, a obra metalinguística e refratária às reificações, segundo uma extrapolação do conceito proposto por Paulo Leminski (1986) acerca da poesia como gênero (quase exclusivo) de negação das apropriações decorativas e mercadológicas.

Trata-se pois do trânsito entre a instrumentalização e a sua refutação ou desvio, sem que qualquer um desses termos possa se reduzir em um valor positivo ou negativo de modo pleno e persistente. Com isso, rearticula-se o aspecto transgressivo, ardiloso, que Vilém Flusser (2007) atribui aos três termos: arte, design e tecnologia. Porém, em lugar do design, a tecnologia assumiria o papel de intermediário, do termo que estabelece as equivalências ou negociações entre os dois outros, em um reposicionamento da tríade apontada por Flusser.

Tal reconfiguração decorre das confluências sustentadas por mídias algorítmicas cada vez mais pervasivas. Deriva tanto das recentes práticas e teorias materialistas e especulativas de cunho projetual ou poético, quanto do caráter pós-digital alcançado pelas mídias em que essas práticas e teorias encontram fundamento e referência. Na condição pós-digital (CRAMER, 2015), a dependência recíproca entre o digital e o analógico é reafirmada. Ganha destaque o encadeamento mútuo e recursivo entre notações discretas, típicas da abstração em registros operacionais, e as manifestações contínuas, análogas aos fenômenos em fluxo do mundo concreto existente.

De modo correspondente, o arte ativismo, o design e a arquitetura críticas se expandem. Suas operações ampliam-se para além das guerrilhas semióticas experimentadas na alucinação consentida via virtualização, como é inicialmente característico da net arte de nomes como a dupla belgo-holandesa Jodi e o esloveno Vuk Cosic. Transcendem ainda o design de interfaces web para movimentos sociais, praticado por grupos como o californiano Design Action Collective, que prosseguem a longa tradição da gráfica de protesto social, também adotada por nomes como o duo francês Bureau d'Etudes. 
No pós-digital, a experiência de interação com a materialidade das coisas passa a atrair os esforços de resistência. Seja nos trabalhos de arte baseados em sistemas interativos com diversos agentes e ambientes, seja no design de interação entre usuários e artefatos inteligentes diversos. Coloca-se em questão a corporalidade, como extensão tátil que manifesta e, ao mesmo tempo, recompõe os cálculos de procedimentos táticos necessários ao ativismo.

Consideraremos aqui ao menos três noções recorrentes sobre essa tatilidade tática. De modo geral, há o comentário sobre as ousadias experimentais, que especulam de modo autorreferente a respeito dos usos e invenções cotidianas em torno dos dispositivos de interação informacional. Dentro dessa vertente, uma opção concerne aos processos participatórios, colaborativos ou de engajamento cívico e ambientalista. Outra opção se dedica à exploração reflexiva acerca dos prováveis benefícios e riscos dos avanços da automação generativa, em contraponto com os processos orgânicos ou naturais.

Vamos considerar a seguir alguns casos que lidam direta ou indiretamente com essas tendências. Comentaremos obras dos coletivos Superflex e !Mediengruppe Bitnik, além de Lucas Bambozzi e Giselle Beiguelman e Julian Oliver. Em seguida, trataremos de trabalhos assinados por Bijari, Novo Estúdio, R(\&)sie\{n\} e Garnet Hertz. Após a apresentação desses casos, dedicaremos a parte final desde ensaio à proposição e discussão sobre o conceito de in-utensílio crítico.

\section{Ativismo na era da participação e generatividade digital}

O coletivo dinamarquês Superflex categoriza a sua produção como conjunto de ferramentas. Em vez de obras predominantemente destinadas à assimilação contemplativa ou aquisitiva, o grupo propõe a invenção de processos e materialidades que possam atender aos requisitos e demandas de determinadas comunidades. No recente Flagship Shelters ${ }^{1}$ (Abrigos Emblemáticos, Figura 1), o coletivo produz em 2015 uma série de versões em escala reduzida de obras arquitetônicos de escritórios renomados.

Trata-se de uma apropriação de projetos elaborados por nomes como a dupla suíça Herzog \& De Meuron e o japonês Toyo Ito, para sediar lojas de grandes marcas de vestuário como Prada e Tod's. Porém, em lugar de atender a uma clientela reduzida, de alto poder aquisitivo, as formas derivadas dessa apropriação se tornam abrigos de construção rápida e de baixo custo, montados com compensados e tecidos para barracas. Primeiro, os modelos são exibidos no Museu de Arte Contemporânea de Tóquio, ao lado de fotos da população sem teto que habita lugares da cidade como o parque Ueno. Em 2016, o projeto é levado para o festival de música Roskilde, na Dinamarca, onde as cabanas são montadas para servir bebidas e oferecer acesso à internet para catadores de garrafas descartadas. 
A tatilidade tática empregada em Flagship Shelters envolve a aplicação de preceitos da cultura de código aberto e faça-você-mesmo. Como em Guarana Power (2003), Copyshop (2005) e outros trabalhos do Superflex, a abordagem de tecnologias de comunicação e de situações de desigualdade socioeconômica é assumida como pretexto para o combate contra as restrições à liberdade de informação. Ao mesmo tempo, coloca-se em questão o acesso elitista a produtos e serviços obtidos a partir dos fluxos comunicacionais, em ciclos que tendem a ser cada vez mais automatizados e menos participativos - se consideramos um sentido de participação mais efetiva, que transcenda a lógica de mercantilização da vida pessoal e dos conteúdos gerados pelo usuário.

Fig 1. Flagship Shelters (Roskilde Festival, 2016), Superflex | Foto: Torben Eskerod | Fonte: http://www.superflex.net/press/label/flagship_shelters.

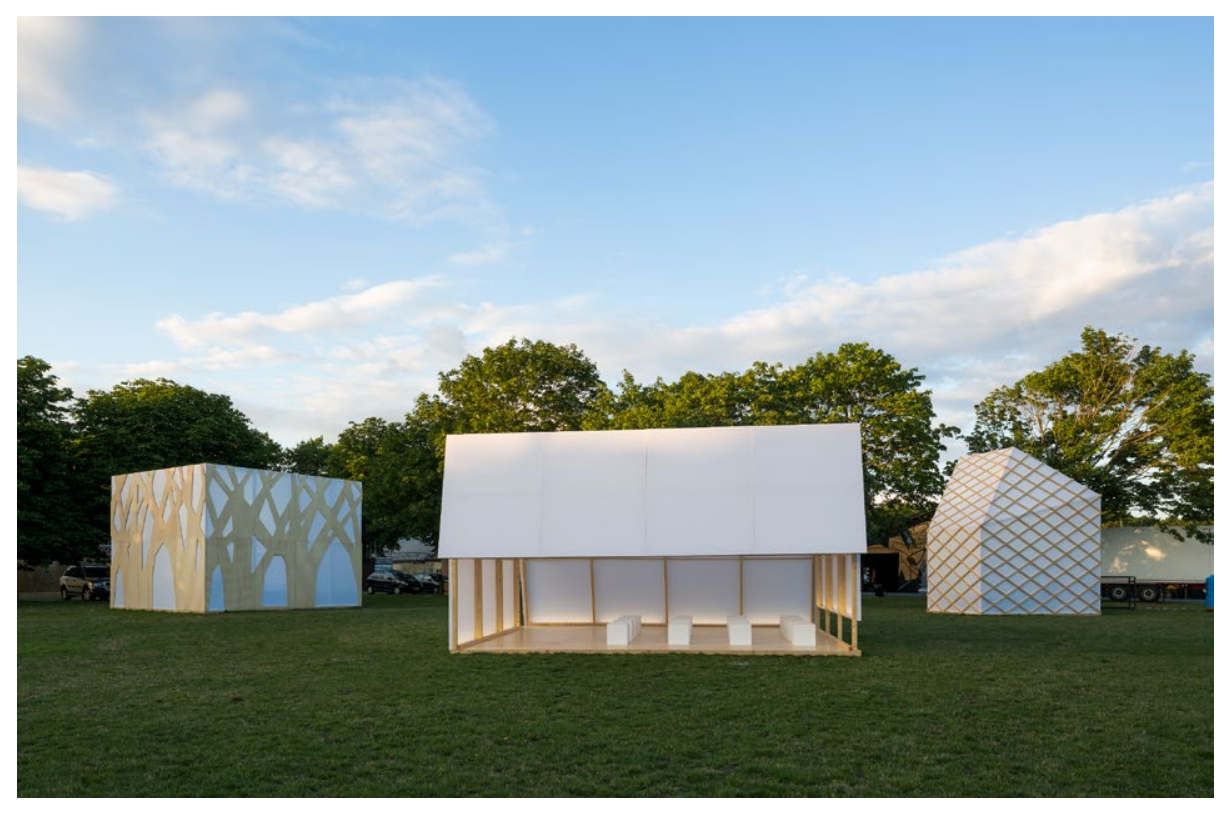

Um caso semelhante é a plataforma itinerante Labmovel ${ }^{2}$ (iniciado em 2012), sob curadoria dos brasileiros Lucas Bambozzi e Gisela Domschke. Nessa iniciativa, artistas e outros convidados levam para as ruas experiências educativas em mídias digitais, a bordo de uma perua modificada. Desse modo, chegam à população de regiões carentes de ofertas culturais temas e práticas experimentais, como as oficinas desmontagem para reestruturação de filmes como Psicose (1960), de Alfred Hitchcock, e Nostalgia (1983), de Andrei Tarkovski. Também são realizadas atividades educativas de projeção mapeada e grafite virtual.

Por sua vez, o arte ativismo do coletivo anglo-suíço !Mediengruppe Bitnik explora as mídias digitais tanto em seus aspectos participativos, quanto especulativos. Com isso, tecem um comentário irônico sobre as condições presentes e eventualmente futuras dos usos das tecnologias. No trabalho Random Darknet Shopper (algo como Comprador Aleatório da Internet Obscura), uma aplicação de software simula a ação de um consumidor 
que utiliza um orçamento semanal de 100 bitcoins para realizar aquisições fortuitas em endereços não indexados pelos motores de busca habituais.

Desde 2014, são adquiridos itens que variam de lacres para revenda de mercadorias violadas, pastilhas de esctasy, maços de cigarro ou conjuntos de chaves mestras. As encomendas são recebidas pelo correio, para ser apresentadas como documentos dos processos ocorridos em um espaço designado para exposição. Além disso, passam a fazer parte de uma coleção formada pelo projeto em si. Lidando com a noção ambígua de arquivo, o coletivo direciona sua crítica ao consumismo das redes. Associa também o sistema da arte com a radicalização desenfreada do livre mercado, facilitando o acesso a produtos tanto corriqueiros, quanto banidos pelas legislações nacionais e internacionais.

Em outra vinculação da arte com a expansão eletrônica do comércio, a brasileira Giselle Beiguelman realiza em 2017 o trabalho Art Supermarket. À maneira de um catálogo, reúnem-se em um site ${ }^{4}$ as imagens de produtos criados a partir da identidade de artistas e de obras de arte famosas, com os respectivos links para os endereços em que é possível comprá-los efetivamente. Entre os itens catalogados estão uma boneca Barbie Andy Warhol, um aparador Monet, taças Frida Kahlo e bolsas Ticiano. A operação também é apresentada fisicamente, em uma instalação no espaço urbano, no formato de uma banca de vendedor ambulante, em que são expostos alguns dos produtos.

Das reificações comerciais da arte é possível passar à exploração política, estética, tecnológica e ambiental da economia. Em HARVEST ${ }^{5}$ (Colheita), o neozelandês Julian Oliver monta em 2017 um sistema em que moinhos de vento geram eletricidade para alimentar um computador destinado à mineração de criptomoedas.

Com o processamento computacional investido na manutenção e verificação pública do livro-razão de transações (os registros criptografados conhecidos como blockchain), o artista obtém recompensa financeira que é revertida para o financiamento de organizações não governamentais engajadas em pesquisas sobre mudanças climáticas.

Nos casos citados, observamos a contestação e o desvio de funcionalidades pretendidas na arquitetura, produção de mídia e sistemas de comércio. Em seu lugar, são propostas alternativas poéticas, estéticas e críticas, que se apoiam na tecnologia visando à invenção ou ao redirecionamento disruptivo de finalidades, em favor de grupos e situações socioambientais sob algum tipo de ameaça ou opressão. Porém, é ainda comum o caminho inverso. Quando intenções projetuais já são desde início pensadas para o ativismo.

Essa predisposição marca a trajetória híbrida do coletivo paulista Bijari. Em trabalhos independentes, patrocinados ou inteiramente comissionados por empresas, o grupo se utiliza de diversas materialidades e processos artesanais, industriais e eletrônicos. A instalação interativa $R e-$ construcidades $^{6}$, de 2007, oferece ao público a possibilidade de montagem individual ou coletiva de paisagens urbanas sonoras e visuais, a partir da disposição de peças sobre uma mesa reativa denominada Reconstructable. 
O projeto propicia a reflexão sobre a atualidade existente e o jogo com outras conformações virtuais da cidade.

Em uma direção igualmente especulativa, o escritório Novo Estúdio, fundado pela arquiteta e urbanista brasiliense Gabriela Bilá, se lança a uma investigação fictícia em Teleport City, de 2017. A premissa assumida é a de imaginar a vida na cidade em um futuro no qual o teletransporte se torna o principal meio de mobilidade de massas. 0 projeto engloba instalações, publicação impressa, web site $e^{7}$ intervenções urbanas e trilha sonora. Com isso, dá materialidade à imaginação acerca das mudanças topológicas, novos modos de habitação, comportamentos sociais e patologias que seriam decorrentes do deslocamento instantâneo.

O conceito de cidade estante, por exemplo, aponta para tipologias de edifícios multifuncionais empilhados, com circulação interna por escadas e elevadores e saltos externos de ponto a ponto por teletransporte. Neles se justapõem moradias, comércio, indústrias e serviços públicos. Essa e outras características da Teleport City dão origem à compulsão de acumuladores culturais, à síndrome ligada à vida exclusiva em fusos noturnos ou diurnos e a grupos de guerrilha armada voltados à preservação de centros históricos e culturas locais.

Também a respeito das relações entre corpo e design, o grupo francês $\mathrm{R}(\&) \operatorname{sie}\{n\}^{8}$ realiza em 2010 o projeto Une architecture des humeurs ${ }^{9}$. Trata-se de uma articulação de conhecimentos de diversas disciplinas como neurobiologia, robótica, matemática e filosofia. 0 trabalho emprega a análise matemática para a criação de estruturas morfológicas relacionais, fundamentadas em conflitos (ou mal-entendidos) entre a expressão verbal dos desejos de eventuais habitantes ou usuários e os dados colhidos em testes bioquímicos sobre a suas reações emocionais. Opõem-se assim a linguagem dos entrevistados aos indicadores obtidos por sensores.

Nessa obra, podemos encontrar um caso típico de produção que estaria excluída do campo da arquitetura, urbanismo e disciplinas de design, segundo os critérios mercadológicos, formalistas e funcionalistas. Também haveria dificuldade em enquadrar o experimento na concepção de ativismo comunitário. Com o projeto de $\mathrm{R}(\&) \operatorname{sie}\{\mathrm{n}\}$, não se espera da racionalidade subjetiva uma resposta completa. A margem irracional inexplicável, captada em operações lógicas e físico-químicas, interfere decisivamente nas "soluções" alcançadas. Nesse sentido, a "arquitetura de humores" se insere com mais facilidade no terreno da arte contemporânea. De fato, é o que ocorreu se consideramos a exibição do trabalho na sede parisiense do centro Le Laboratoire, dedicado à arte e ao design experimental.

Por fim, o canadense Garnet Hertz realiza Disobedient Electronics: Protest $^{10}$ em 2016, uma curadoria sobre a produção crítica de designers, artistas, hackers e makers de dez países diferentes. 0 trabalho pretende demonstrar que a fabricação de objetos eletrônicos pode ser adotada como meio eficaz de resistência. Ao mesmo tempo, coloca em dúvida o potencial de combate das vertentes de design crítico e especulativo inspiradas nas teorias dos bri- 
tânicos Anthony Dunne e Fiona Raby (2013). Em lugar delas, Hertz defende a busca pela compreensão e engajamento por meio de argumentos e fatos amplamente acessíveis ao público.

Em uma publicação diagramada como catálogo, revista e manual, Disobedient Electronics reúne propostas como Knitted Radio ${ }^{11}$ (Rádio Tricotado, de 2014), de autoria da artista turca Ebru Kurbak e da alemã Irene Posch. Trata-se literalmente da técnica de construção de um transmissor de FM a partir da inserção de fios condutores entre os pontos da trama de uma blusa. $O$ aparelho é destinado a facilitar a comunicação em contextos de vigilância e opressão violenta. Sua fonte de inspiração é a onda de protestos ocorrida na Turquia em 2013, mobilização inicialmente contrária à demolição do Parque Taksim Gezi, em Istambul, que ganha uma multidão de apoiadores em um contexto de forte repressão policial.

Outro projeto incluído em Disobedient Electronics é chamado de THERO. Concebido entre 2016 e 2017 pelos espanhóis Román Torre e Ángeles Angulo, apresenta-se como um objeto de caráter escultural que carrega um dispositivo capaz de bloquear ou criptografar fluxos de comunicação, conforme é girado pelo usuário. A peça visa facilitar a proteção da privacidade sobre dados intangíveis a partir da simplicidade do gesto sobre a materialidade, em uma conjugação do sentido tático com o aspecto tátil do ativismo pós-digital.

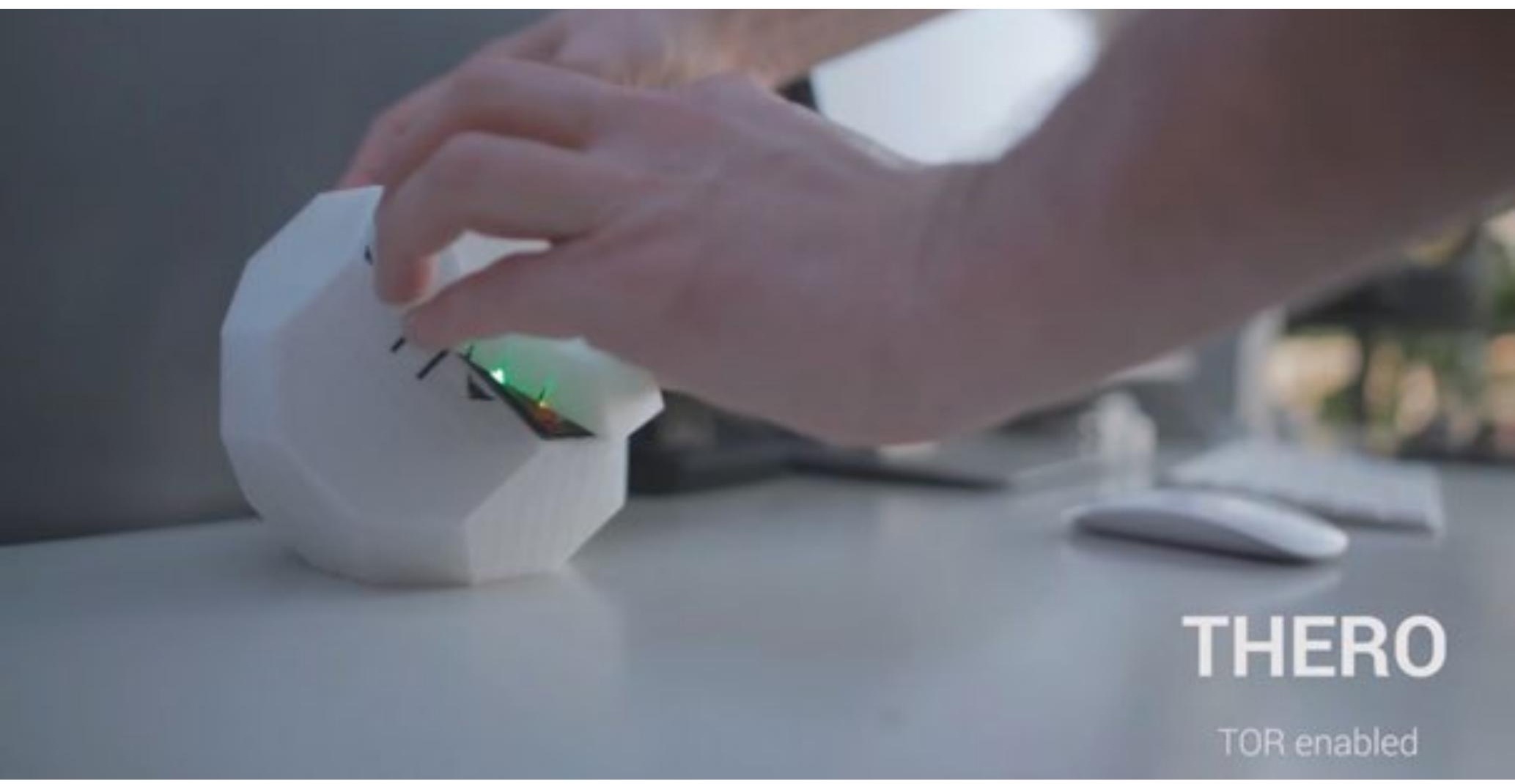

Fig 2. THERO (primeiro protótipo, 2017), Román Torre e Ángeles Ângulo Extraído de vídeo de Román Torre |Fonte: https://vimeo.com/rtorre 


\section{In-utensílio crítico}

É frequente que paradoxos relativos à diferenciação de sistemas se apresentem na compreensão do ativismo nas artes visuais, design e arquitetura. Um desses paradoxos diz respeito à verificação de quais contextos, objetos, agentes são autorizados o não autorizados em dado campo. Nas artes visuais, espera-se algum grau mínimo de autonomia, baseada na expectativa habitual de que a produção e consumo de suas obras se sustentem, mesmo que precariamente, sem depender das influências alheias e das ponderações de consequências. No design e arquitetura, admite-se que há um propósito exterior a ser cumprido, que impele à renúncia ao experimentalismo extremo, ou a sua redução à ideia de ensaio tolerado enquanto teste para uma futura aplicação efetiva.

Em casos como os que foram comentados acima, o ativismo encontra espaço quando tais características de autossuficiência ou de comprometimento são transgredidas, de um lado ou de outro. No contexto pós-digital, essa disrupção diz respeito à facilitação tecnológica dos processos participatórios que envolvem instâncias físicas e virtuais de (inter)ação, como nas ações do Labmóvel ou nas instalações de Reconstrucidades e Teleport City.

Por outro lado, a disrupção refere-se também à automação generativa de comportamentos interativos e inteligentes que envolvem o humano e o não humano em agenciamentos cíbridos - cibernéticos e híbridos, entre o informacional e o material (BEIGUELMAN, 2004). São exemplos dessa tendência o sistema automatizado de compras Random Darknet Shopper e o minerador de criptomoedas para fundos ambientalistas HARVEST.

Diante desses exemplos, parece haver uma transversalidade paradoxal no modo como as noções participatórias e generativas se aplicam, em termos práticos ou teóricos. Tanto no que se refere ao arte ativismo, quanto ao design e a fabricação crítica - ou seja, o critical design pretendido pelos britânicos Dunne \& Raby e o critical making do canadense Matt Ratto, seguido por Garnet Hertz. Por conta disso, torna-se comum o intercâmbio das realizações tecnológicas de cada campo, o que provoca significações inesperadas de estranhamento ou desfamiliarização ante os hábitos projetuais e poéticos.

Projetos de arte ativismo passam a ser compreendidos como instâncias de preparação e teste de instrumentos e métodos de resistência destinados à adoção por interessados. Como se Flagship Shelters, Art Supermarket e outros exemplos semelhantes ocupassem a mesma condição de um gesto de design experimental. Por sua vez, a produção e o design críticos de THERO e Knitted Radio geram casos mais propensos às exposições, ao debate e à apropriação sociocultural, do que às linhas de produção voltadas ao atendimento comercial e em escala das necessidades de clientela elitista ou indiscriminada. 
Essa ambiguidade poderia indicar a consolidação de um novo sistema das artes. Ele seria caracterizado não mais pela indistinção clássica ou pela cisão moderna entre artes aplicadas e artes não aplicadas. Em vez disso, seria marcado pela "unificação [dois ideias de liberdade, imaginação e criatividade] com a facilidade, o serviço e a função", conforme Larry Shiner (2014: 410-413).

Contudo, segundo o reposicionamento da tríade comentada por Flusser (2007), a função intermediária da tecnologia não parece suficiente para apagar as diferenças entre o poético e o projetual. De fato, as diferenças se acentuam, sobretudo, quando gestos de ativismo ganham evidência. Pois, já de partida, o ativismo coloca em disputa a própria partilha do sensível nas artes, isto é, aquilo que concerne à política da estética, na forma de posições e valores ocupados por modalidades singulares de produção artística (RANCIÈRE, 2000).

Essa distribuição de modalidades artísticas nos remete à noção de sistema que essas manifestações compõem. Sistema que pode ser compreendido como subconjunto de um todo - o sistema das artes como parcela dos sistemas sociais comunicativos, como em Niklas Luhmann (2000). Mas que também pode servir como (contra)modelo paralelo, que ampara a consideração análoga e critica dos demais arranjos e divisões sociais, conforme Rancière (2000).

Nesse sentido, a transversalidade do ativismo na arte, design e arquitetura deriva de uma função paradoxal de in-utensílio crítico, expressão que compomos a partir de Paulo Leminski (1986). Essa função diz respeito à refutação e reconfiguração da divisão, partilha ou crítica, feita em proveito das noções organizadoras, porém, provisórias e instáveis, acerca do que se considera projetual ou poético. Segundo a ideia de in-utensílio crítico, a utilidade e a inutilidade seriam parcelamentos intercambiáveis de categorização. Não são ontologicamente essenciais, pois são instanciados pelos contextos e as operações de cisão que são neles adotadas.

Tais operações críticas são próximas da etimologia da qualificação hacker que assumem a arte e o design, sobretudo quando pensadas no atual contexto tecnológico (GÓMEZ, 2016). Pois o verbo hackear (to hack) é derivado da ideia de corte brusco, feito a golpes com instrumentos incisivos. Por analogia com a fragmentação da materialidade tátil, esse corte diferencia as táticas da imaterialidade dos código. Constituem-se assim artifícios, ou seja, meios de transgressão, o aspecto ardiloso que une etimologicamente a arte, o design e a tecnologia, segundo Flusser (2007).

Enquanto in-utensilio crítico, o ativismo se desenrola como cisão heteróclita sobre os sistemas e seus aspectos estéticos e éticos. Essa cisão é, autopoiética, pelo desvio dos próprios fazeres artísticos, com seus sujeitos, objetos e modos de apreensão. Mas, ao mesmo tempo, é alopoiética, por impulsionar a contravenção das regras do jogo dos regimes de poder, que correspondem igualmente a sujeitos, objetos e modos de apreensão em um sentido mais abrangente. 
O ativismo poético e projetual da época pós-digital se fundamenta nessa estética disruptiva (MARKUSSEN, 2013), de hackeamento. Por meio dela, efetua-se a transgressão de materialidades e retóricas orientadas por hierarquias preestabelecidas, relativas às artes visuais e ao design, arquitetura e urbanismo. Persiste, contudo, o ímpeto de distinção entre campos de atuação artística. Divisão que, paradoxalmente, se reconstitui para, depois, encadear outros ciclos de questionamento e ativismo.

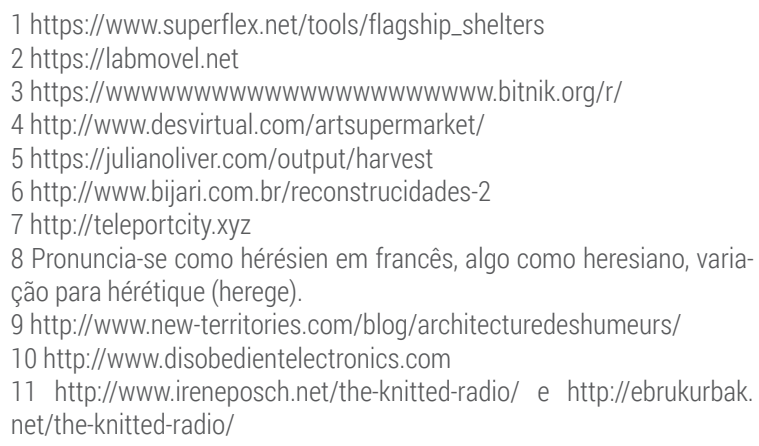

\section{Bibliografia}

BEIGUELMAN, Giselle. Admirável Mundo Cíbrido. Academia.edu. 2004. PDF. Disponível em: <https://www.academia.edu/3003787/Admirável_mundo_cíbrido>. Acesso em: 29 jun. 2018. CRAMER, Florian. What Is "Post-Digital"? In: BERRY, David M. (David Michael); DIETER, Michael (Org.). Postdigital Aesthetics: Art, Computation And Design. London: Palgrave Macmillan, 2015. p. 12-26.

DUNNE, Anthony; RABY, Fiona. Speculative Everything: Design, Fiction, and Social Dreaming. Cambridge: The MIT Press, 2013.

FLUSSER, Vilém. O Mundo Codificado: por uma Filosofia do Design e da Comunicação. São Paulo: CosacNaify, 2007.

GÓMEZ, Diego. El Diseñador como Hacker. RChD: creación y pensamiento, Santiago, n. 2, p. 96-105, 23 ago. 2016. Disponível em: <http://www.rchd.uchile.cl/index.php/RChDCP/ article/view/42708>.

LEMINSKI, Paulo. A arte e outros inutensílios. Folha de S. Paulo, São Paulo, 18 out. 1986. , p. 92, caderno Ilustrada.

LUHMANN, Niklas. Art as a social system. Stanford: Stanford University Press, 2000.

MARKUSSEN, Thomas. The disruptive aesthetics of design activism: Enacting design between art and politics. Design Issues, Cambridge, USA, v. 29, n. 1, p. 38-50, 2013. Disponível em: <http://www.mitpressjournals.org/doi/abs/10.1162/DESI_a_00195>.

Recebido: 10 de março de 2019. Aprovado: 10 de abril de 2019.
RANCIÈRE, Jacques. Le partage du sensible : esthétique et politique. Paris: La Fabrique éd, 2000.

SHINER, Larry. La invención del arte: una historia cultural. Barcelona: Paidós, 2014. 